\title{
Dietary Biotin Supplementation Modifies Hepatic Morphology without Changes in Liver Toxicity Markers
}

\author{
Leticia Riverón-Negrete, ${ }^{1}$ Gloria Sicilia-Argumedo, ${ }^{1}$ Carolina Álvarez-Delgado, ${ }^{1,2}$ \\ Elvia Coballase-Urrutia, ${ }^{3}$ Jonathan Alcántar-Fernández, ${ }^{1}$ and Cristina Fernandez-Mejia ${ }^{1}$ \\ ${ }^{1}$ Unidad de Genética de la Nutrición, Instituto de Investigaciones Biomédicas, Universidad Nacional Autónoma de México, \\ Instituto Nacional de Pediatría, Avenida del Imán 1, 4th Floor, Colonia Insurgentes Cuicuilco, 04530 Mexico City, Mexico \\ ${ }^{2}$ Centro de Investigación Científica y de Educación Superior de Ensenada, Carretera Ensenada-Tijuana No. 3918, Zona Playitas, \\ 22860, Ensenada, BC, Mexico \\ ${ }^{3}$ Laboratorio de Neurosciencias, Instituto Nacional de Pediatría, Avenida del Imán 1, 3rd Floor, Colonia Insurgentes Cuicuilco, \\ 04530 Mexico City, Mexico
}

Correspondence should be addressed to Cristina Fernandez-Mejia; crisfern@biomedicas.unam.mx

Received 7 October 2016; Revised 28 November 2016; Accepted 30 November 2016

Academic Editor: Marija Mostarica-Stojković

Copyright (C) 2016 Leticia Riverón-Negrete et al. This is an open access article distributed under the Creative Commons Attribution License, which permits unrestricted use, distribution, and reproduction in any medium, provided the original work is properly cited.

\begin{abstract}
Pharmacological concentrations of biotin have pleiotropic effects. Several reports have documented that biotin supplementation decreases hyperglycemia. We have shown that a biotin-supplemented diet increased insulin secretion and the mRNA abundance of proteins regulating insulin transcription and secretion. We also found enlarged pancreatic islets and modified islet morphology. Other studies have shown that pharmacological concentrations of biotin modify tissue structure. Although biotin administration is considered safe, little attention has been given to its effect on tissue structure. In this study, we investigated the effect of biotin supplementation on hepatic morphology and liver toxicity markers. Male BALB/cAnN Hsd mice were fed a control or a biotinsupplemented diet for 8 weeks. Versus the control mice, biotin-supplemented mice had an altered portal triad with dilated sinusoids, increased vascularity, and bile conducts. Furthermore, we observed an increased proportion of nucleomegaly and binucleated hepatocytes. In spite of the liver morphological changes, no differences were observed in the serum liver damage indicators, oxidative stress markers, or antioxidant enzymes. Our data demonstrate for the first time that biotin supplementation affects liver morphology in normal mice, and that these modifications are not paralleled with damage markers.
\end{abstract}

\section{Introduction}

The physiological role of the vitamin biotin (also named B7) is to participate as a coenzyme of carboxylases [1]. The adequate intake (AI) level of biotin is $30 \mu \mathrm{g} / \mathrm{d}$ for adults [2]. It has been well documented that biotin affects gene expression and systemic functions at pharmacological levels, which are approximately 30 to 650 times its daily requirement [3].

Pharmacological doses of biotin have hypolipidemic [48] and hypoglycemic effects [7, 9-12] and reduce diabetes complications [11-13] in both animal models and humans. These effects are associated with changes in gene and protein expression $[12,14-18]$ in key metabolic organs, such as the liver and the pancreatic islets.
In previous studies in our laboratory, normal mice fed a biotin-supplemented diet for 8 weeks demonstrated increased insulin secretion and higher levels of mRNAs involved in the control of insulin transcription and secretion compared with mice fed a biotin-sufficient diet [15]. Interestingly, biotin supplementation induced an increase in islet size and modified its typical architecture of alpha-cells at the periphery and beta-cells at the core [15].

Other studies have shown that pharmacological doses of biotin modify tissue morphology. Our research group previously demonstrated that treatment with pharmacological concentrations of biotin decreases the number of primary and Graafian follicles in female mice [19]. Consistent with this effect of biotin on reproductive structures, acute biotin 
treatment induced atrophy in the corpora lutea of female rats [20]. In male rats, biotin supplementation for 6 weeks decreased total sperm counts as well as the diameter of the seminiferous tubes [21]. In animal models of diabetes, biotin supplementation ameliorated the histopathological morphology in the liver [12, 22], kidney [23], and pancreas [12].

Because of biotin's effects on glucose and lipid metabolism, supplements and medications containing pharmacological amounts of the vitamin are commercially available $[8,24]$. Although biotin supplementation is considered safe [25], little attention has been paid to its effect on tissue structure. In this study we investigated the effects of biotin supplementation on hepatic morphology and liver toxicity markers.

\section{Materials and Methods}

2.1. Animal Model and Experimental Design. All interventions were approved by the Ethical Committee for Experimentation of the Biomedical Research Institute of the National Autonomous University of Mexico. At weaning three-week-old male Balb/cAnN mice were fed one of the following diets: biotin-control (TD-01362) or biotinsupplemented diet (TD-02458) containing $1.76 \mathrm{mg}$ and $97.70 \mathrm{mg}$ of free biotin/kg diet, respectively (Harlan Teklad, Madison WI, USA) as described previously [15-18, 26]. A third group of mice received the control diet but were treated with a single dose of carbon tetrachloride $\left(\mathrm{CCl}_{4}, 2 \mathrm{ml} / \mathrm{kg}\right.$ body weight) to induce liver damage. Food consumption and body weight were measured through the experiment. After 8 weeks, the mice were deprived of food for $12 \mathrm{~h}$ and anesthetized as described in [15-18], and the blood and liver were extracted. The mice were killed via cervical dislocation.

2.2. Analysis of Serum Aspartate Aminotransferase, Alanine Aminotransferase, Gamma-Glutamyltransferase, Alkaline Phosphatase, Total and Direct Bilirubin, Albumin, and Urea. Blood samples were collected and centrifuged at $1600 \times \mathrm{g}$ and $4^{\circ} \mathrm{C}$ for $10 \mathrm{~min}$. Sera were stored at $-20^{\circ} \mathrm{C}$ until used. Hemolyzed samples were discarded to avoid interference with the assays. The compounds were quantified by colorimetric assays (Spinreact, Sant Esteve de Bas, Spain) according to the manufacturer's protocol and were expressed as U/L.

2.3. Lipid Peroxidation. Lipid peroxidation was quantified in liver homogenates by assaying malondialdehyde using the thiobarbituric acid by method [27]. Briefly, liver homogenates were incubated with thiobarbituric acid, heated by boiling for $45 \mathrm{~min}$, and kept in ice for $15 \mathrm{~min}$, followed by a centrifugation at $3000 \times \mathrm{g}$ for $10 \mathrm{~min}$, twice. The supernatant was read at $532 \mathrm{~nm}$. The malondialdehyde levels were reported in $\mu \mathrm{mol} / \mathrm{mg}$ of protein.

2.4. Glutathione Content. Immediately after the mice were sacrificed, liver samples were washed in a saline isotonic solution to eliminate remnant blood, homogenized in 5\% ice-cold metaphosphoric acid (1/20 w/v) (Sigma Aldrich, St. Louis, MO, USA), and centrifuged at $12000 \mathrm{rpm}$ at $4^{\circ} \mathrm{C}$ for $15 \mathrm{~min}$. The supernatant was collected and kept on ice. Glutathione was quantified spectrophotometrically at $405 \mathrm{~nm}$ with the HT Glutathione Assay Kit (Trevigen, St Louis, MO, USA) according to the manufacturer's recommendations. The concentration of reduced gluthatione (GSH) was calculated using a GSH standard curve. Oxidized glutathione contents were determined by subtracting the amount of GSH from the level of total glutathione.

2.5. Superoxide Dismutase Activity. Approximately $100 \mathrm{mg}$ of liver was homogenized with a glass potter homogenizer in an ice-cold saline isotonic solution. Tissue extracts were centrifuged at $12500 \times \mathrm{g}$ for $30 \mathrm{~min}$ at $4^{\circ} \mathrm{C}$ to remove insoluble material, and the protein concentration was measured using a Bio-Rad protein assay following the manufacturer's instructions. Super oxide dismutase activity was quantified in liver homogenates with a commercial kit based on xanthine oxidase and a color agent according to the protocol provided by the manufacturer (Sigma Aldrich, San Louis, MO, USA).

2.6. Catalase Activity. Catalase activity was measured according to Góth, 1991 [28], with slight modifications. The liver was homogenized in phosphate buffer $(0.1 \mathrm{M}, \mathrm{pH} 7.00)$. Ten $\mu \mathrm{g}$ of total protein was incubated for $30 \mathrm{sec}$. in phosphate buffer ( $0.1 \mathrm{M}, \mathrm{pH} 7.0$, and $12 \mathrm{mM}$ of hydrogen peroxide). The reaction was stopped by addition of $32.4 \mathrm{mM}$ ammonium molybdate. Reactions were read at $405 \mathrm{~nm}$, and the specific activity was calculated.

2.7. Histological Analysis. The livers were dissected and fixed in $10 \%$ neutral formalin, dehydrated in ascending grades of alcohol, and embedded in paraffin wax. Consecutive $5 \mu \mathrm{m}$ thick sections were cut, mounted on glass slides, and stained with hematoxylin and eosin.

Two slides were prepared for each mouse. These contained three sections of each liver. Ten field areas for each section were randomly selected and examined for histological changes $(25 \mathrm{x})$ under light microscope. The random field areas were scored as follows: normal appearance $(-)$, minimal cellular disruption in less than $1 \%$ of field area, mild cellular disruption of $1 \%-30 \%$ of field area, moderate cellular disruption of $31 \%-60 \%$ of field area, severe cell disruption of $61 \%-$ $90 \%$ of field area, and very severe cellular disruption of $91 \%-$ $100 \%$ of field area [29].

To assess binucleated hepatocytes and nucleomegaly, three field areas of six sections were taken from 9 mice in each group. These were analyzed at 40x in an Olympus BX51 microscope. The analyses were performed simultaneously by two persons who were blinded to the group identity.

2.8. Nitric Oxide Concentration. Liver homogenates were prepared as described above and were treated with proteinase $\mathrm{K}[10 \mathrm{mg} / \mathrm{ml}]$ to remove interfering proteins. Quantification was performed with a commercial kit (Thermo Scientific, Rockford, ILL, USA) for the indirect determination of nitrites 
TABLE 1: Effect of eight weeks of biotin supplementation on serum liver damage indicators.

\begin{tabular}{lccc}
\hline Enzyme/metabolite & Units & Control & Biotin-supplemented \\
\hline Aspartate aminotransferase & {$[\mathrm{U} / \mathrm{L}]$} & $163 \pm 11.0$ & $196 \pm 8.60^{*}$ \\
Alanine aminotransferase & {$[\mathrm{U} / \mathrm{L}]$} & $32.9 \pm 3.29$ & $30.2 \pm 2.40$ \\
Gamma-glutamyltransferase & {$[\mathrm{U} / \mathrm{L}]$} & $2.77 \pm 0.38$ & $2.48 \pm 0.50$ \\
Alkaline phosphatase & {$[\mathrm{U} / \mathrm{L}]$} & $164 \pm 11.0$ & $196 \pm 8.63$ \\
Total bilirubin & {$[\mu \mathrm{mol} / \mathrm{L}]$} & $0.30 \pm 0.040$ & $0.22 \pm 0.029$ \\
Indirect bilirubin & {$[\mu \mathrm{mol} / \mathrm{L}]$} & $0.29 \pm 0.071$ & $0.22 \pm 0.020$ \\
Albumin & {$[\mathrm{mg} / \mathrm{dL}]$} & $3.28 \pm 0.26$ & $2.57 \pm 0.24$ \\
Urea & {$[\mathrm{mg} / \mathrm{dL}]$} & $52.3 \pm 1.21$ & $50.7 \pm 1.89$ \\
\hline
\end{tabular}

Values are mean \pm SEM. $n=7-10 .{ }^{*} p<0.050$.

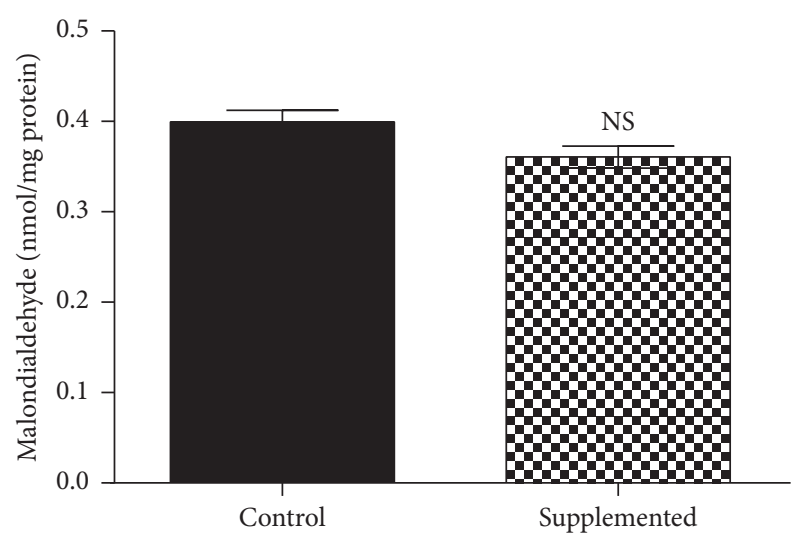

(a)

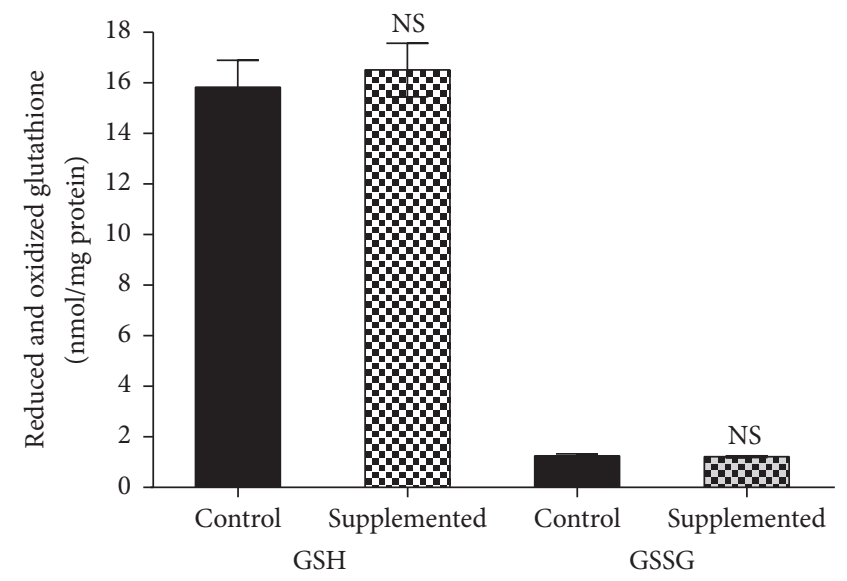

(b)

FIGURE 1: Effect of biotin supplementation on liver malondialdehyde and reduced and oxidized glutathione in mice fed a biotin-supplemented diet for 8 weeks. (a) Malondialdehyde concentrations. Values represent the mean \pm SEM of 5 mice from each group. (b) Reduced and oxidized glutathione. Black bars: control group; patterned bars: biotin-supplemented group. Values represent the mean \pm SEM of 8 mice from each group. All measurements were performed in triplicate. ${ }^{\mathrm{NS}} p>0.050$.

and nitrates in biological samples using nitrate reductase and the Griess reagent that absorbs visible light at $540 \mathrm{~nm}$.

2.9. Statistical Analysis. Statistical analyses were performed using the Statview statistical analysis program and GraphPad Prism 6.0 software (Berkeley, CA, USA). All data are presented as the mean \pm SEM; $n$ is the number of evaluated subjects. Statistical significance was assessed by Student's $t$-test or 1-way ANOVA. $p$ values less than 0.050 were considered statistically significant.

\section{Results}

3.1. Effect of Biotin Supplementation on Serum Liver Damage Indicators. We studied how biotin supplementation influenced liver enzyme tests (Table 1). The data show increased aspartate aminotransferase (AST) levels in the biotin-supplemented group $(p<0.050)$; however, the values were in the normal range (55.0-352 U/L) [30]. No differences were seen between the control and the supplemented group in gamma-glutamyltransferase (GGT), alanine aminotransferase (ALT), alkaline phosphatase (ALP), total and direct bilirubin, albumin, and urea. As expected, all parameters were significantly $(p<0.050)$ affected in the carbon tetrachloride group compared with both the control and supplemented groups: AST $=954 \pm 23.6 \mathrm{U} / \mathrm{L} ; \mathrm{GGT}=9.91$ $\pm 0.78, \mathrm{ALP}=223 \pm 7.60 \mathrm{U} / \mathrm{L} ; \mathrm{ALT}=833 \pm 13.2$; bilirubin $1.22 \pm 0.28[\mu \mathrm{mol} / \mathrm{L}]$; indirect bilirubin $1.02 \pm 0.18[\mu \mathrm{mol} / \mathrm{L}]$; albumin $4.86 \pm 0.34[\mathrm{~g} / \mathrm{dL}]$; urea $108 \pm 8.33[\mathrm{mg} / \mathrm{dL}]$.

3.2. Effects of Biotin Supplementation on Oxidative Stress Markers and Antioxidant Enzymes Activities. We also evaluated the effects of biotin supplementation on lipid peroxidation and oxidized and reduced glutathione. Eight weeks of biotin supplementation did not modify malondialdehyde concentrations versus the control group (Figure 1(a); control $=0.40 \pm 0.016$; supplemented $=0.36 \pm 0.015 \mathrm{nmol} / \mathrm{mg}$ protein). In the carbon tetrachloride group, the levels were significantly increased $(p<0.050)$ compared with the control and supplemented groups $\left(\mathrm{CCl}_{4}=0.51 \pm 0.020 \mathrm{nmol} / \mathrm{mg}\right.$ protein).

Glutathione is a major antioxidant that protects tissues from free radical injury. The analysis of glutathione concentrations (Figure 1(b)) showed that the levels of the reduced 


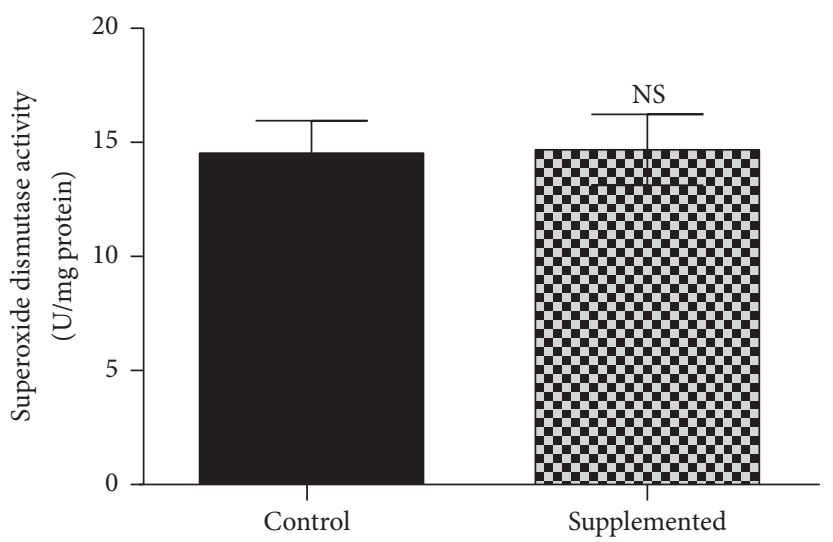

(a)

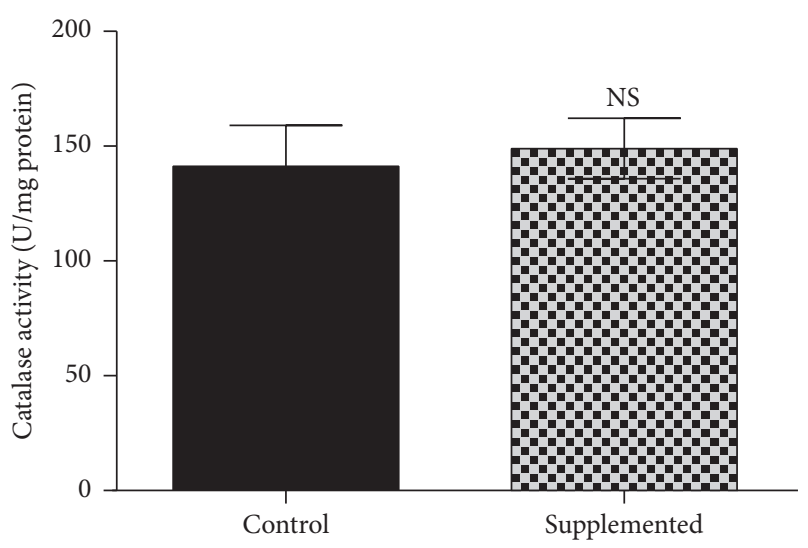

(b)

FIGURE 2: Effect of biotin supplementation on superoxide dismutase and catalase activity in mice fed a biotin-supplemented diet for 8 weeks. (a) Liver superoxide dismutase activity. Values represent the mean \pm SEM of 5 mice from each group. (b) Liver catalase activity. Black bars: control group; patterned bars: biotin-supplemented group. Values represent the mean \pm SEM of 9 mice from each group. All measurements were performed in triplicate. ${ }^{\mathrm{NS}} p>0.050$.

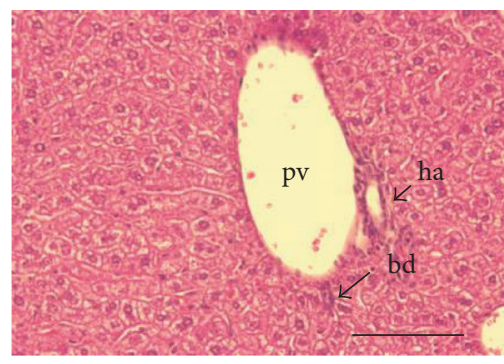

(a)
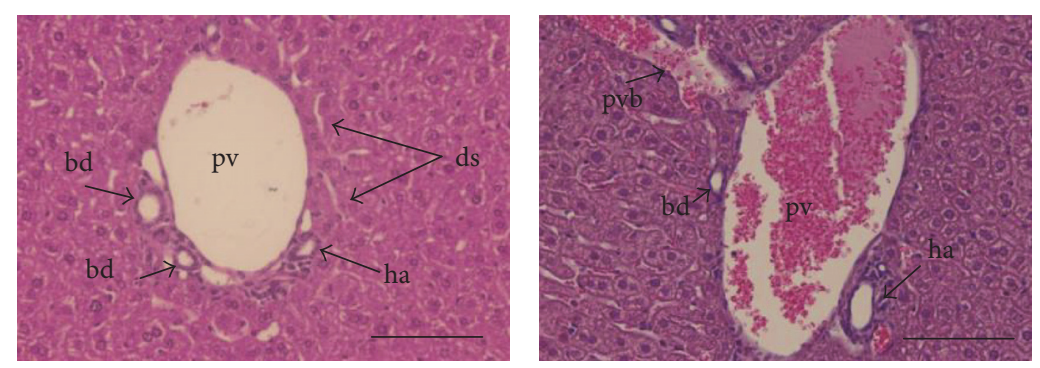

(b)

FIGURE 3: Effect of biotin supplementation on liver morphology in mice fed a biotin-supplemented diet for 8 weeks. Paraffin sections stained by hematoxylin and eosin. (a) Control group's representative image showing a normal portal triad. (b) Supplemented group. Left panel: representative image, showing an altered triad with dilated sinusoids and increased number of bile ducts. Right panel: enlarged portal vein with adjacent portal vein branch. pv: portal vein; ha: hepatic artery; bd: bile duct; ds: dilated sinusoids; pvb: portal vein branch. Scale bar represents $100 \mu \mathrm{m}$.

and the oxidized forms did not significantly differ between the control and supplemented group (reduced glutathione: control $=15.9 \pm 1.06$; supplemented $=16.6 \pm 1.06 \mathrm{nmol} / \mathrm{mg}$ protein; oxidized glutathione, control $=1.25 \pm 0.079$; supplemented $1.22 \pm 0.030 \mathrm{nmol} / \mathrm{mg}$ protein; in the carbon tetrachloride control group, values were increased $(p<$ $0.050)$ compared with the control and supplemented groups (reduced glutathione $=10.0 \pm 0.75 \mathrm{nmol} / \mathrm{mg}$ protein; oxidized glutathione $=7.52 \pm 1.20 \mathrm{nmol} / \mathrm{mg}$ protein); the oxidative stress index was calculated using the ratio between reduced glutathione/oxidized glutathione). The oxidative stress index for both groups was indicative of no oxidative stress (12.7 \pm 0.90 and $13.6 \pm 0.90$, respectively; $p>0.050$ ). In contrast, the stress index for the carbon tetrachloride was significantly different $(p<0.050)$ compared to the control and the supplemented groups (carbon tetrachloride $=1.33 \pm 0.31$ ).

Liver superoxide dismutase activity (Figure 2(a)) showed no significant differences between the biotin-supplemented group and the control group: control $=14.8 \pm 1.45$; supplemented $=15.0 \pm 1.48 \mathrm{U} / \mathrm{mg}$ protein. Increased enzyme activity was found in the carbon tetrachloride positive control values $(25.4 \pm 1.86 \mathrm{U} / \mathrm{mg}$ protein; $p<0.050$ compared with the control and the supplemented groups). Catalase activity (Figure 2(b)) did not significantly differ between the control and supplemented group, control $=144 \pm 18.1$; supplemented $=151 \pm 13.5 \mathrm{U} / \mathrm{mg}$ protein. The carbon tetrachloride positive control values showed increased catalase activity (286 \pm $30.1 \mathrm{U} / \mathrm{mg}$ protein, $p<0.050$ compared with the control and supplemented groups).

\subsection{Effect of Biotin Supplementation on Liver Morphology.} Despite the fact that biotin supplementation had no effect on liver toxicity markers, histological analysis showed noticeable differences between groups. Light microscopy observations of livers from control mice showed a normal morphology with adjacent normal sized sinusoids radiating from the central veins toward the periphery of the liver lobules and a normal portal triad (Figure 3(a)). In the supplemented mice, we observed an altered portal triad. Morphological evaluation revealed moderate dilated sinusoids, moderate 


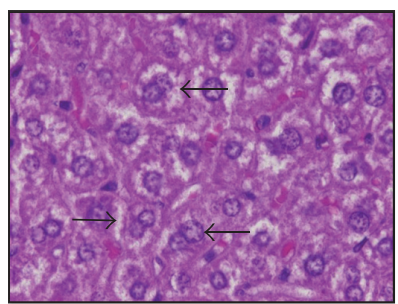

Control

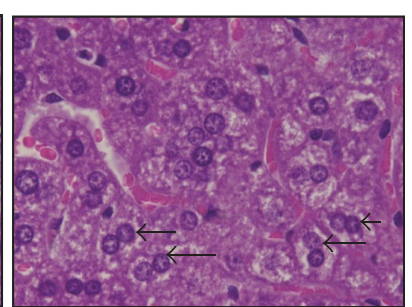

Biotin-supplemented

(a)

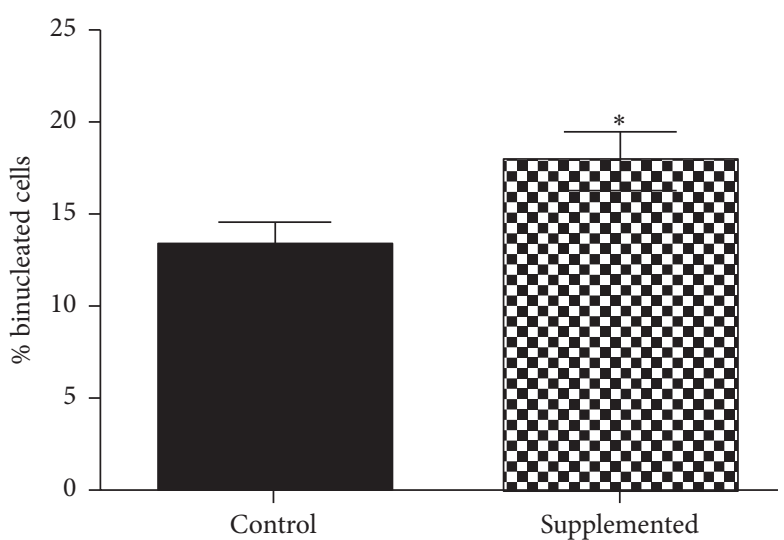

(b)

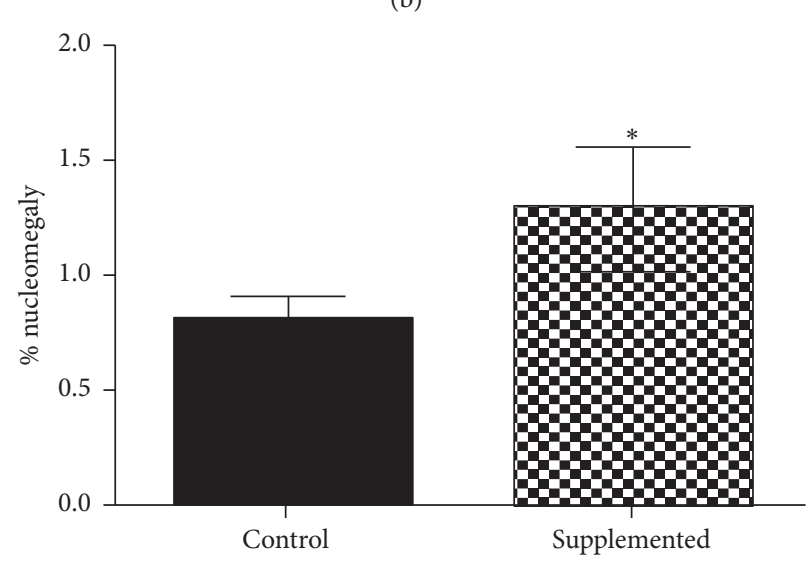

(d)

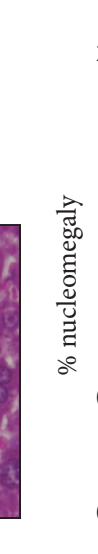

(c)

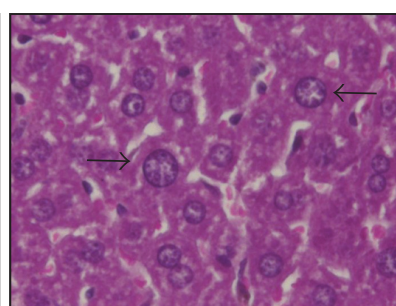

(c)

FIGURE 4: Effect of biotin supplementation on binucleated hepatocytes and nucleomegaly in mice fed a biotin-supplemented diet for 8 weeks. (a) Hematoxylin and eosin representative image of hepatocytes from control and biotin-supplemented group (right) showing mono and binucleated hepatocytes. (b) Quantification of binucleated hepatocytes per field. (c) Hematoxylin and eosin images of hepatocytes from control and biotin-supplemented group (right) showing nuclei $<12$ and $>12 \mu \mathrm{m}$. (d) Nuclei quantification $>12 \mu \mathrm{m}$ per field. Black bars: control group; patterned bars: biotin-supplemented group. Values represent the mean \pm SEM of 9 mice per group. ${ }^{*} p<0.050$ compared to the control group.

increased vascularity, and mild increased number of bile conducts (Figure 3(b)).

Changes were also observed in the hepatocyte nuclei. Compared to the mice fed a control diet, the biotinsupplemented group showed a $39 \%$ increase in the number of binucleated hepatocytes (control = 13.2 \pm 1.29 ; supplemented $=18.7 \pm 1.50 \%$ ) (Figures $4(\mathrm{a})$ and $4(\mathrm{~b})$ ). In addition, the number of hepatocytes with nucleomegaly (nuclei $>12 \mu \mathrm{m}$ ) was increased: control $=0.81 \pm 0.11$; supplemented $=1.30 \pm$ $0.28 \%$ (Figures $4(\mathrm{c})$ and $4(\mathrm{~d})$ ).

3.4. Effects of Biotin Supplementation on Nitric Oxide Levels. The increased vascularization observed in histology prompted us to determine nitric oxide concentrations because nitric oxide has been proposed to participate in the biotin transduction signaling pathway cGMP/PKG [31]. However, no differences were found in nitric oxide concentration between the control and the supplemented group (Figure 5): control $=24.5 \pm 0.55$; supplemented $=25.6$ \pm 1.50. Carbon tetrachloride levels were increased: $64.3 \pm$
$7.17 \mu \mathrm{mol} / \mathrm{mg}$ tissue; $p<0.050$, compared with the control and supplemented groups.

\section{Discussion}

In this study, we found that eight weeks of dietary biotin supplementation induced noticeable changes in liver morphology in normal mice and that these modifications were not paralleled with liver damage markers. The biotinsupplemented mice had a higher percentage of dilated sinusoids, vascularity, and bile ducts compared with the controls. We also found an increased number of binucleated hepatocytes (about 39\%) and hepatocytes with nucleomegaly (66\%) in the biotin-supplemented mice compared with the controls. These results together with previous results in pancreatic islets [15] and ovaries [19] and the observations by other groups $[12,21-23]$ indicate that pharmacological concentrations of biotin modify tissue structure.

Binucleated hepatocytes and nucleomegaly are the result of polyploidy [32]. At present, the role of increased polyploidy 


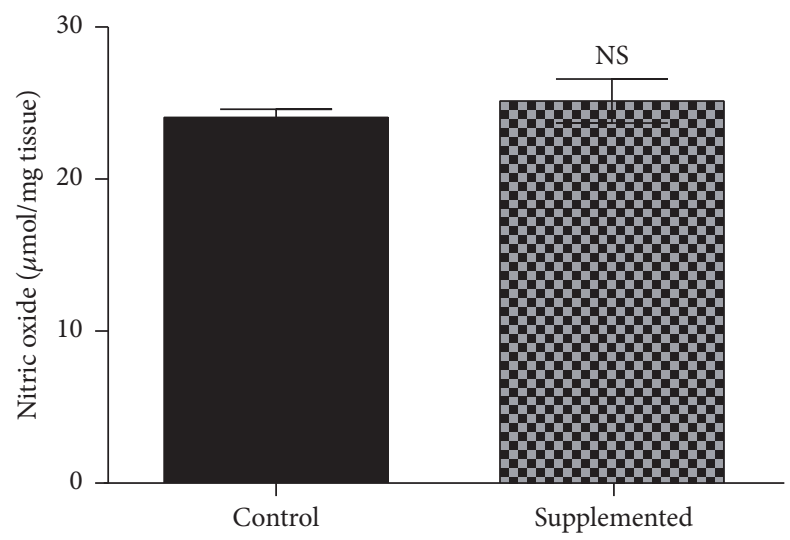

FIGURE 5: Effect of biotin supplementation on nitric oxide concentrations in mice fed a biotin-supplemented diet for 8 weeks. Values represent the mean \pm SEM of 9 mice from each group. Measurements were performed in triplicate. Black bars: control group; patterned bars: biotin-supplemented group. ${ }^{\mathrm{NS}} p>0.050$.

in the liver is still under debate $[33,34]$. Polyploid cells are generated in some types of cancer such as esophageal and colon cancers [32]; however, in the liver, most of the studies suggest that this mechanism renders the cells more resistant to injury and enhances the liver's functional capacity $[32,34]$. Our findings show that, despite increased polyploidy, serum damage indicators, oxidative stress markers, and antioxidant enzymes were not affected by biotin supplementation, suggesting that the hepatocyte nuclear changes produced by the vitamin might be related to the positive effects associated with liver polyploidy. However, further studies will be required to test this hypothesis.

In previous studies, we observed that normal mice fed a biotin-supplemented diet (approximately $13.5 \mathrm{mg} / \mathrm{kg}$ body weight) showed increased pancreatic islet size as well as increased alpha-cells at the islet center compared with the controls [15]. However, these structural changes did not have adverse effects on islet function. Our prior studies [19] in the same mouse model showed changes in response to biotin in the female reproductive tract, with decreased Graafian and ovarian primary follicles. Neither our prior studies $[15,19]$ nor this work (data not shown) identified unfavorable effects of biotin supplementation on body weight, food consumption, external appearance, or behavior.

Changes on ovary histology were also observed by Paul et al. [20] in response to acute intraperitoneal treatment of $50 \mathrm{mg} / \mathrm{kg}$ body weight of biotin [20]. Consistent with our experiments, they found that biotin did not affect normal body weight gain [20]; however, in contrast with our observations [19], they found estrus cycle irregularities. Sawamura et al. [21], found that rats fed a diet containing $10 \mathrm{~g}$ biotin/ $\mathrm{kg}$ diet for 6 weeks ( $990 \mathrm{mg} / \mathrm{kg}$ body weight) presented diminished total sperm counts and seminiferous tubule diameters compared to pair-fed rats. However, the biotin-supplemented group showed reduced food intake, impaired body weight gain, and decreased kidney and liver weights. It is possible that the histological modifications might result from biotin toxic effects because the magnitude of biotin intake is above the reported tolerable upper intake level found by the same investigators [35].

Other investigations found that biotin supplementation modified the histopathological features produced in the diabetic state $[12,22,23]$. In rats with diabetes induced by 2 weeks of high-fat diet (HFD) and a single dose of streptozotocin that were then fed a HFD supplemented with biotin $(300 \mu \mathrm{g} / \mathrm{kg}$ body weight per d) over 10 weeks, studies by Sahin et al. [12] noted that the histopathological changes in the liver, kidney, and pancreas of diabetic rats were reverted with biotin supplementation. Male Swiss albino mice with streptozotocin-induced diabetes treated daily by oral gavage with $15 \mathrm{mg} / \mathrm{kg}$ of biotin for 12 successive days had improved kidney and liver damage associated with the diabetic state $[22,23]$. In the kidney, biotin supplementation decreased the number of distorted glomeruli, inflammatory cells, and giant macrophages [23]. In the liver, biotin caused reductions in dilated portal vein, leukocytic infiltration, and fatty degeneration [22]. It is interesting to note that while in diabetic models the effect of biotin reverses altered tissue structure produced by the pathological diabetic state, in normal animals the changes are observed on the typical morphology. None of the previous works showed the liver histology changes shown in the present report.

Despite the effects of biotin on liver morphology, our data did not find changes on liver damage indicators such as albumin, total and direct bilirubin, gamma-glutamyltransferase, alanine aminotransferase, alkaline phosphatase, or urea. These results agree with studies in normal rats showing that diets containing up to $1,000 \mathrm{mg} / \mathrm{kg}$ diet did not affect these parameters [21]. These data indicate that pharmacological concentrations of biotin do not affect classic liver damage tests. However, we cannot rule out the possibility that the histological changes observed here might affect liver physiology in other ways.

The reversion of altered tissue structure induced by biotin in diabetic animal models is associated with reduced oxidative stress $[12,22,23]$. In rats with diabetes induced by a highfat diet and streptozotocin, serum, liver, and kidney malondialdehyde levels were decreased in biotin-treated animals [12]. Additionally, the protein expression of the active form of $\mathrm{NF}-\mathrm{kB}-\mathrm{a}$ transcription factor involved in cellular responses to diverse inflammation stimuli including free radicalsdiminished in both, liver and kidney [12]. In Swiss albino diabetic mice, biotin treatment decreased the immunereaction response toward acrolein immunohistochemicalsignal-an indicator of oxidative damage [22, 23]. However, in our study, biotin supplementation had no effect on liver malondialdehyde levels or other oxidative stress markers such as reduced and oxidized glutathione. In agreement with this, no statistical significant differences were observed on the antioxidant activity of superoxide dismutase and catalase. The difference in biotin effects between normal and pathological states has also been observed in gene expression $[12,14,17,36$, $37]$ and insulin and glucose tolerance $[15,38]$, indicating that the pharmacological effects of biotin can vary depending on the metabolic status.

Nitric oxide has an important role in vasodilatation [39]. Studies in Jurkat cells have found that the effects of biotin 
are dependent of nitric oxide concentrations [31]. However, other studies in rats receiving eight weeks of biotin in water (approximately $1.2 \mathrm{mg} / \mathrm{kg}$ body weight) indicate that biotin effects are independent of nitric oxide [40]. Our data did not find changes in the concentration of nitric oxide suggesting that other mechanisms are involved in the vasodilatation changes observed here.

The mechanisms involved in biotin-induced histological changes are largely unknown. In pancreatic islets, we found that the changes produced by biotin supplementation on islet architecture might be related to diminished expression of the neural cell adhesion protein Ncaml, whose decreased expression produces changes in islet morphology and generates an increased number of alpha-cells at the interior of the islet [41]. Current studies in our laboratory are focused on the molecular mechanisms responsible for the morphological changes observed in the liver in response to biotin supplementation.

Biotin products with pharmacological concentrations of biotin are commercially available. Biotin administration is considered harmless in humans and rodents [25]. Toxicity tests such as the Ames test [42-44] in bacteria found that biotin was neither toxic nor mutagenic. Nonetheless, a Tradescantia-micronucleus bioassay showed mutagenic effects with a minimum effective dose of approximately $250 \mathrm{mg} / \mathrm{ml}$ [45]. In humans, no adverse effects were found with administration of 0.25 to $100 \mathrm{mg}$ biotin. A lack of adverse effects has been reported in patients with inborn errors of biotin metabolism [46], normal individuals [24], diabetic patients [10, 13], and patients undergoing hemodialysis [11]. Rats fed diets containing up to $1,000 \mathrm{mg} / \mathrm{kg}$ diet did not show liver damage [21]. Although pharmacological concentrations of biotin are considered safe, further investigations are required to determine the effects of the tissue structure changes observed in this study.

\section{Conclusion}

Our data shows for the first time that biotin supplementation affects liver morphology in normal mice and that these modifications are not paralleled with changes in classical liver damage indicators and oxidative stress markers. These results indicate that biotin toxicity studies need to be addressed with different tools because the pharmacological concentrations of biotin affect tissue morphology and have nuclei effects.

\section{Competing Interests}

The authors declare that there are no competing interests regarding the publication of this paper.

\section{Acknowledgments}

Dr. Rodolfo Rodríguez-Jurado, Dr. Rosa María ViguerasVillaseñor of Laboratorio Biología de la Reproducción, and $\mathrm{M}$ en $\mathrm{C}$ Gerardo Barragán-Mejía of Laboratorio Neurociencias acknowledge Instituto Nacional de Pediatría Departamento de Patología, for histology facilities. The authors are grateful to Dr. Maria Eugenia Gonsebatt Bonaparte,
Dr. José Pedraza Chaverri, and Dr. Javier Espinosa Aguirre for valuable discussions throughout these studies, and to M. en C. Betzabé Linares Ferrer for computer assistance. This work is supported by research grant from the Consejo Nacional de Ciencia y Tecnología, 219787-M and 99294-M, and Fondos Federales 074/2013. M. en C. Leticia RiverónNegrete is a doctoral student from the Doctorado en Ciencias Biológicas at Universidad Nacional Autónoma de México (UNAM). Jonathan Alcántar-Fernández is a doctoral student from the Programa de Doctorado en Ciencias Biomédicas, Universidad Nacional Autónoma de México, and was the recipient of Fellowship 384151 from Consejo Nacional de Ciencia y Tecnología (CONACYT), México.

\section{References}

[1] P. S. Harper, "C.R. Scriver, A.L. Beaudet, W.S. Sly, D. Valle (eds.), B. Childs, K.W. Kinzler, B. Vogelstein (associate eds.): molecular and metabolic bases of inherited disease, 8th edition," Human Genetics, vol. 110, no. 2, pp. 205-206, 2002.

[2] A. A. Yates, S. A. Schlicker, and C. W. Suitor, "Dietary Reference Intakes: the new basis for recommendations for calcium and related nutrients, B vitamins, and choline," Journal of the American Dietetic Association, vol. 98, no. 6, pp. 699-706, 1998.

[3] C. Fernandez-Mejia and M.-L. Lazo-de-la-Vega-Monroy, "Biological effects of pharmacological concentrations of biotin," Journal of Evidence-Based Complementary and Alternative Medicine, vol. 16, no. 1, pp. 40-48, 2011.

[4] C. Revilla-Monsalve, I. Zendejas-Ruiz, S. Islas-Andrade et al., "Biotin supplementation reduces plasma triacylglycerol and VLDL in type 2 diabetic patients and in nondiabetic subjects with hypertriglyceridemia," Biomedicine and Pharmacotherapy, vol. 60 , no. 4, pp. 182-185, 2006.

[5] O. K. Dokusova and I. V. Krivoruchenko, "The effect of biotin on the level of cholesterol in the blood of patients with atherosclerosis and essential hyperlipidemia," Kardiologiia, vol. 12, no. 12, p. 113, 1972.

[6] M. W. Marshall, P. G. Kliman, V. A. Washington, J. F. Mackin, and B. T. Weinland, "Effects of biotin on lipids and other constituents of plasma of healthy men and women," Artery, vol. 7, no. 4, pp. 330-351, 1980.

[7] M. Hemmati, H. Babaei, and M. Abdolsalehei, "Survey of the effect of biotin on glycemic control and plasma lipid concentrations in type 1 diabetic patients in Kermanshah in Iran (2008-2009)," Oman Medical Journal, vol. 28, no. 3, pp. 195-198, 2013.

[8] C. Albarracin, B. Fuqua, J. Geohas, M. Finch, and J. Komorowski, "Improvement in glycemic control, lipids and insulin sensitivity with the combination of chromium picolinate and biotin in type 2 diabetes mellitus," Diabetes Care, vol. 54, article A428, 2005.

[9] J. C. Coggeshall, J. P. Heggers, M. C. Robson, and H. Baker, "Biotin status and plasma glucose in diabetics," Annals of the New York Academy of Sciences, vol. 447, pp. 389-392, 1985.

[10] M. Maebashi, Y. Makino, Y. Furukawa, K. Ohinata, S. Kimura, and T. Sato, "Therapeutic evaluation of the effect of biotin on hyperglycemia in patients with non-insulin dependent diabetes mellitus," Journal of Clinical Biochemistry and Nutrition, vol. 14, no. 3, pp. 211-218, 1993.

[11] D. Koutsikos, C. Fourtounas, A. Kapetanaki et al., "Oral glucose tolerance test after high-dose i.v. biotin administration in 
normoglucemic hemodialysis patients," Renal Failure, vol. 18, no. 1, pp. 131-137, 1996.

[12] K. Sahin, M. Tuzcu, C. Orhan et al., "Anti-diabetic activity of chromium picolinate and biotin in rats with type 2 diabetes induced by high-fat diet and streptozotocin," British Journal of Nutrition, vol. 110, no. 2, pp. 197-205, 2013.

[13] D. Koutsikos, B. Agroyannis, and H. Tzanatos-Exarchou, "Biotin for diabetic peripheral neuropathy," Biomedicine \& Pharmacotherapy, vol. 44, no. 10, pp. 511-514, 1990.

[14] Y. Sugita, H. Shirakawa, R. Sugimoto, Y. Furukawa, and M. Komai, "Effect of biotin treatment on hepatic gene expression in streptozotocin-induced diabetic rats," Bioscience, Biotechnology and Biochemistry, vol. 72, no. 5, pp. 1290-1298, 2008.

[15] M. L. Lazo de la Vega-Monroy, E. Larrieta, M. S. German, A. Baez-Saldana, and C. Fernandez-Mejia, "Effects of biotin supplementation in the diet on insulin secretion, islet gene expression, glucose homeostasis and beta-cell proportion," Journal of Nutritional Biochemistry, vol. 24, no. 1, pp. 169-177, 2013.

[16] A. Aguilera-Méndez and C. Fernández-Mejía, "The hypotriglyceridemic effect of biotin supplementation involves increased levels of cGMP and AMPK activation," BioFactors, vol. 38, no. 5, pp. 387-394, 2012.

[17] E. Larrieta, F. Velasco, P. Vital et al., "Pharmacological concentrations of biotin reduce serum triglycerides and the expression of lipogenic genes," European Journal of Pharmacology, vol. 644, no. 1-3, pp. 263-268, 2010.

[18] D. Boone-Villa, A. Aguilera-Méndez, A. Miranda-Cervantes, and C. Fernandez-Mejia, "Effects of biotin supplementation in the diet on adipose tissue cGMP concentrations, AMPK activation, lipolysis, and serum-free fatty acid levels," Journal of Medicinal Food, vol. 18, no. 10, pp. 1150-1156, 2015.

[19] A. Báez-Saldaña, I. Camacho-Arroyo, J. J. Espinosa-Aguirre et al., "Biotin deficiency and biotin excess: effects on the female reproductive system," Steroids, vol. 74, no. 10-11, pp. 863-869, 2009.

[20] P. K. Paul, P. N. Duttagupta, and H. C. Agarwal, "Effects of an acute dose of biotin on the reproductive organs of the female rat," Current Science, vol. 42, no. 6, pp. 206-208, 1973.

[21] H. Sawamura, C. Ikeda, R. Shimada, Y. Yoshii, and T. Watanabe, "Dietary intake of high-dose biotin inhibits spermatogenesis in young rats," Congenital Anomalies, vol. 55, no. 1, pp. 31-36, 2015.

[22] B. A. Aldahmash, D. M. El-Nagar, and K. E. Ibrahim, "Attenuation of hepatotoxicity and oxidative stress in diabetes STZinduced type 1 by biotin in Swiss albino mice," Saudi Journal of Biological Sciences, vol. 23, no. 2, pp. 311-317, 2016.

[23] B. A. Aldahmash, D. M. El-Nagar, K. E. Ibrahim, and M. S. Metwaly, "Biotin amelioration of nephrotoxicity in streptozotocininduced diabetic mice," Saudi Journal of Biological Sciences, vol. 22, no. 5, pp. 564-569, 2015.

[24] G. M. Singer and J. Geohas, "The effect of chromium picolinate and biotin supplementation on glycemic control in poorly controlled patients with type 2 diabetes mellitus: a placebocontrolled, double-blinded, randomized trial," Diabetes Technology and Therapeutics, vol. 8, no. 6, pp. 636-643, 2006.

[25] M. Z. Fiume, "Final report on the safety assessment of Biotin," International Journal of Toxicology, vol. 20, supplement 4, pp. $1-12,2001$.

[26] A. Báez-Saldaña and E. Ortega, "Biotin deficiency blocks thymocyte maturation, accelerates thymus involution, and decreases nose-rump length in mice," Journal of Nutrition, vol. 134, no. 8, pp. 1970-1977, 2004.
[27] H. H. Draper and M. Hadley, "Malondialdehyde determination as index of lipid peroxidation," Methods in Enzymology, vol. 186, pp. 421-431, 1990.

[28] L. Góth, "A simple method for determination of serum catalase activity and revision of reference range," Clinica Chimica Acta, vol. 196, no. 2-3, pp. 143-151, 1991.

[29] S. A. Mansour and A. H. Mossa, "Adverse effects of lactational exposure to chlorpyrifos in suckling rats," Human and Experimental Toxicology, vol. 29, no. 2, pp. 77-92, 2010.

[30] C. R. Laboratories, BALB/c Nude Mouse Biochemistry, 2012, http://www.criver.com/files/pdfs/rms/balbc-nude/rm_rm_r balb-c_nude_mouse_clinical_pathology_data.aspx.

[31] R. Rodriguez-Melendez and J. Zempleni, "Nitric oxide signaling depends on biotin in Jurkat human lymphoma cells," Journal of Nutrition, vol. 139, no. 3, pp. 429-433, 2009.

[32] G. Gentric and C. Desdouets, "Polyploidization in liver tissue," The American Journal of Pathology, vol. 184, no. 2, pp. 322-331, 2014.

[33] G. Gentric and C. Desdouets, "Liver polyploidy: Dr Jekyll or Mr Hide?” Oncotarget, vol. 6, no. 11, pp. 8430-8431, 2015.

[34] A. W. Duncan, "Aneuploidy, polyploidy and ploidy reversal in the liver," Seminars in Cell and Developmental Biology, vol. 24, no. 4, pp. 347-356, 2013.

[35] H. Sawamura, T. Fukuwatari, and K. Shibata, "Effects of excess biotin administration on the growth and urinary excretion of water-soluble vitamins in young rats," Bioscience, Biotechnology and Biochemistry, vol. 71, no. 12, pp. 2977-2984, 2007.

[36] G. Ferreira and W. P. Weiss, "Effect of biotin on activity and gene expression of biotin-dependent carboxylases in the liver of dairy cows," Journal of Dairy Science, vol. 90, no. 3, pp. 14601466, 2007.

[37] K. Dakshinamurti and W. Li, “Transcriptional regulation of liver phosphoenolpyruvate carboxykinase by biotin in diabetic rats," Molecular and Cellular Biochemistry, vol. 132, no. 2, pp. 127-132, 1994.

[38] A. Reddi, B. DeAngelis, O. Frank, N. Lasker, and H. Baker, "Biotin supplementation improves glucose and insulin tolerances in genetically diabetic KK mice," Life Sciences, vol. 42, no. 13, pp. 1323-1330, 1988.

[39] V. Bhandari, R. Choo-Wing, S. P. Chapoval et al., "Essential role of nitric oxide in VEGF-induced, asthma-like angiogenic, inflammatory, mucus, and physiologic responses in the lung," Proceedings of the National Academy of Sciences of the United States of America, vol. 103, no. 29, pp. 11021-11026, 2006.

[40] M. Watanabe-Kamiyama, S. Kamiyama, K. Horiuchi et al., "Antihypertensive effect of biotin in stroke-prone spontaneously hypertensive rats," British Journal of Nutrition, vol. 99, no. 4, pp. 756-763, 2008.

[41] F. Esni, I.-B. Täljedal, A.-K. Perl, H. Cremer, G. Christofori, and H. Semb, "Neural cell adhesion molecule (N-CAM) is required for cell: type segregation and normal ultrastructure in pancreatic islets," Journal of Cell Biology, vol. 144, no. 2, pp. 325337, 1999.

[42] S. Hayes, A. Gordon, I. Sadowski, and C. Hayes, "RK bacterial test for independently measuring chemical toxicity and mutagenicity: Short-term forward selection assay," Mutation Research/Environmental Mutagenesis and Related Subjects, vol. 130, no. 2, pp. 97-106, 1984.

[43] SRI-International, "Microbial mutagenesis testing of substances compound report: F76-041, D-Biotin,” NTIS Report PB89169072, 1979. 
[44] M. D. Ronquillo-Sánchez, R. Camacho-Carranza, C. Fernandez-Mejia, S. Hernández-Ojeda, M. Elinos-Baez, and J. J. Espinosa-Aguirre, "Modulation of the rat hepatic cytochrome P4501A subfamily using biotin supplementation," BioMed Research International, vol. 2013, Article ID 627907, 9 pages, 2013.

[45] T.-H. Ma, M. M. Harris, V. A. Anderson et al., "Tradescantiamicronucleus (Trad-MCN) tests on 140 health-related agents," Mutation Research/Genetic Toxicology, vol. 138, no. 2-3, pp. 157167, 1984.

[46] E. R. Baumgartner and T. Suormala, "Multiple carboxylase deficiency: inherited and acquired disorders of biotin metabolism," International Journal for Vitamin and Nutrition Research, vol. 67, no. 5, pp. 377-384, 1997. 

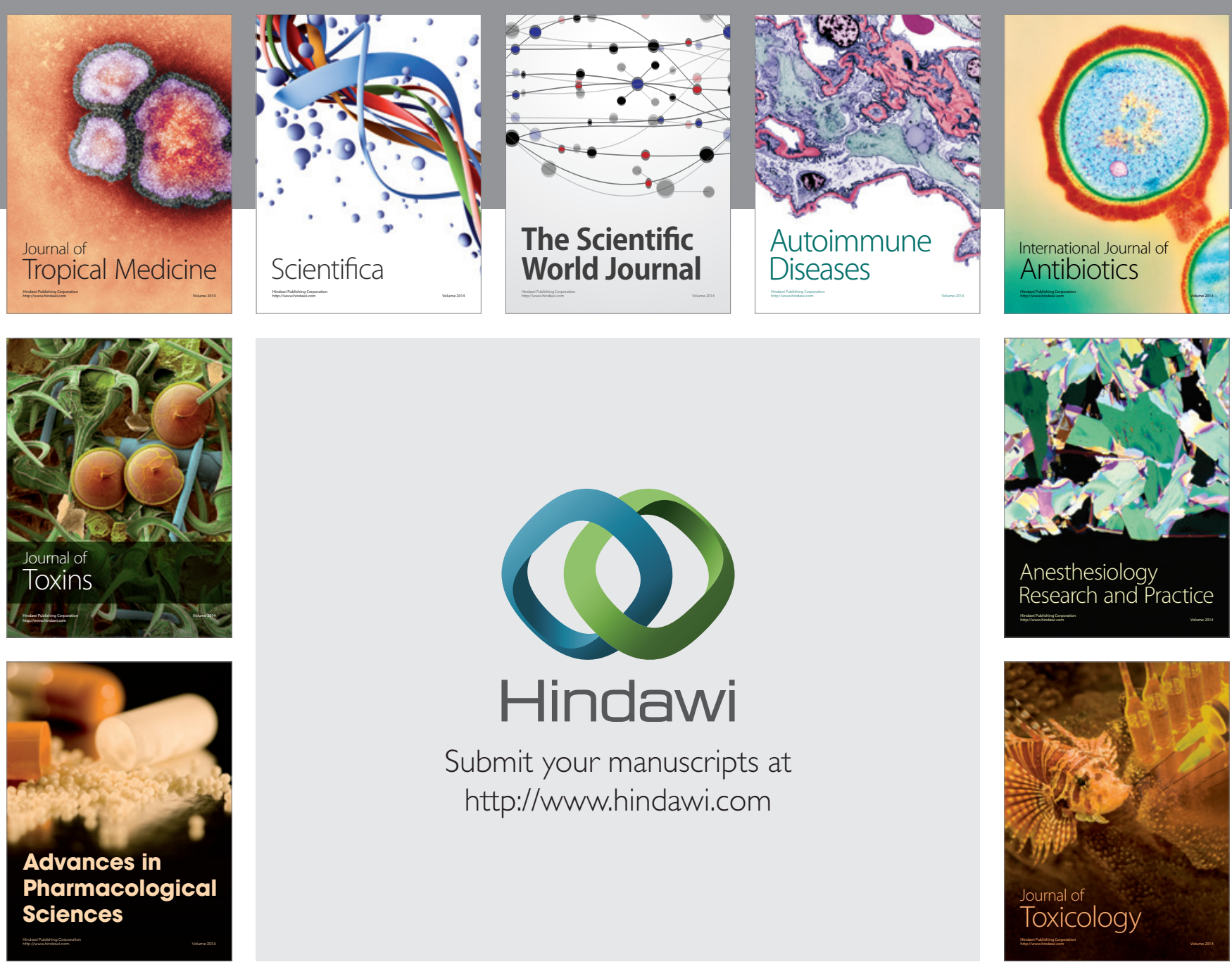

\section{Hindawi}

Submit your manuscripts at

http://www.hindawi.com
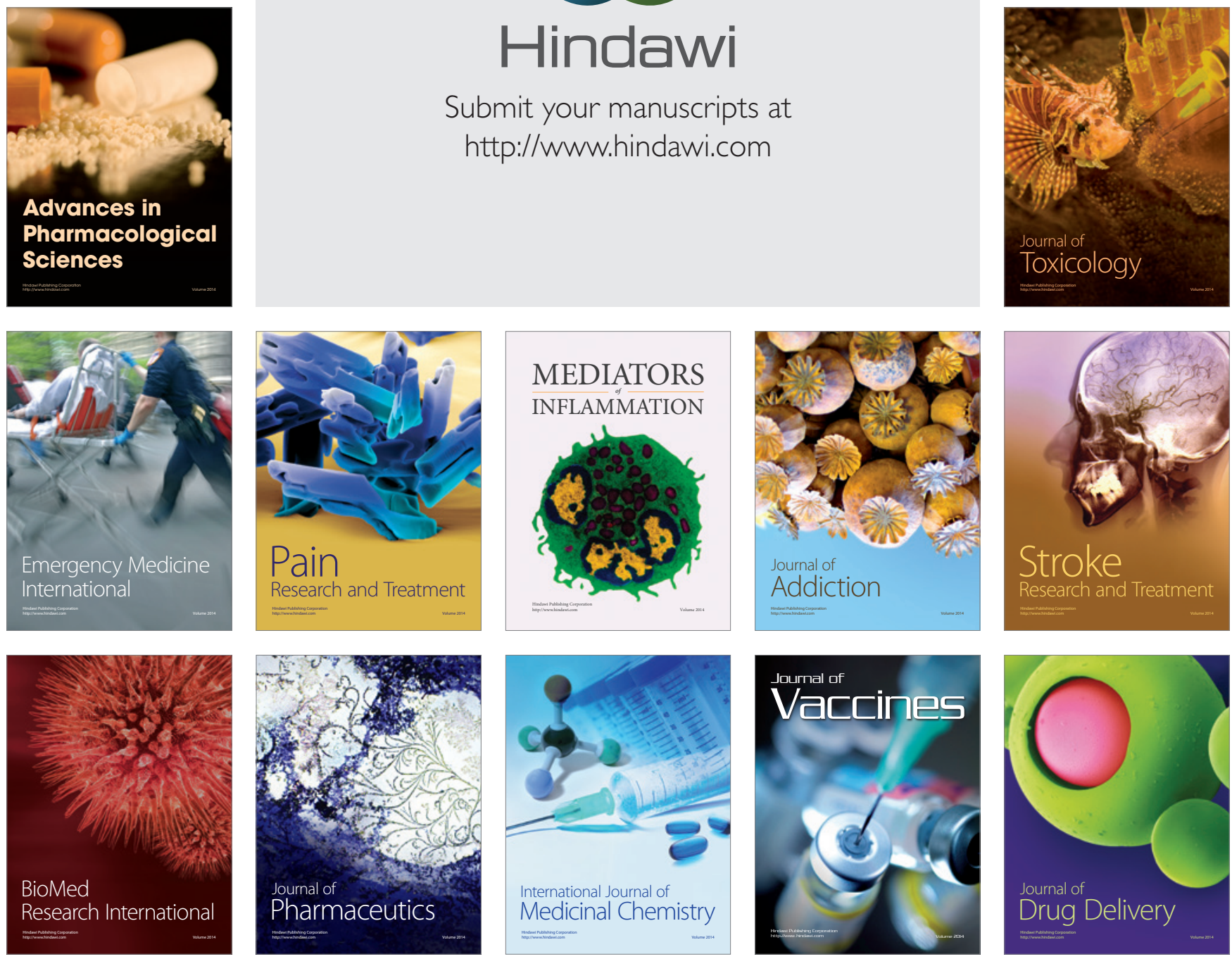